\title{
Phosphatase ABI1 and okadaic acid- sensitive phosphoprotein phosphatases inhibit salt stress-activated SnRK2.4 kinase
}

Ewa Krzywińska ${ }^{1,2}$, Maria Bucholc ${ }^{1}$, Anna Kulik1, Arkadiusz Ciesielski 1,3, Małgorzata Lichocka', Janusz Dębski ${ }^{1}$, Agnieszka Ludwików ${ }^{4}$, Michał Dadlez ${ }^{1,5}$, Pedro L. Rodriguez ${ }^{6}$ and Grażyna Dobrowolska ${ }^{1 *}$

\begin{abstract}
Background: SNF1-related protein kinases 2 (SnRK2s) are key regulators of the plant response to osmotic stress. They are transiently activated in response to drought and salinity. Based on a phylogenetic analysis SnRK2s are divided into three groups. The classification correlates with their response to abscisic acid (ABA); group 1 consists SnRK2s non-activated in response to ABA, group 2, kinases non-activated or weakly activated (depending on the plant species) by ABA treatment, and group 3, ABA-activated kinases. The activity of all SnRK2s is regulated by phosphorylation. It is well established that clade A phosphoprotein phosphatases 2C (PP2Cs) are negative regulators of ABA-activated SnRK2s, whereas regulators of SnRK2s from group 1 remain unidentified.
\end{abstract}

Results: Here, we show that ABI1, a PP2C clade A phosphatase, interacts with SnRK2.4, member of group 1 of the SnRK2 family, dephosphorylates Ser158, whose phosphorylation is needed for the kinase activity, and inhibits the kinase, both in vitro and in vivo. Our data indicate that $A B I 1$ and the kinase regulate primary root growth in response to salinity; the phenotype of $A B / 1$ knockout mutant (abiltd) exposed to salt stress is opposite to that of the snrk2.4 mutant. Moreover, we show that the activity of SnRK2s from group 1 is additionally regulated by okadaic acid-sensitive phosphatase(s) from the phosphoprotein phosphatase (PPP) family.

Conclusions: Phosphatase ABI1 and okadaic acid-sensitive phosphatases of the PPP family are negative regulators of salt stress-activated SnRK2.4. The results show that ABI1 inhibits not only the ABA-activated SnRK2s but also at least one ABA-non-activated SnRK2, suggesting that the phosphatase is involved in the cross talk between ABA-dependent and ABA-independent stress signaling pathways in plants.

Keywords: Salinity, Osmotic stress signaling, SNF1-related protein kinases 2, SnRK2, Phosphoprotein phosphatases, Arabidopsis thaliana, ABI1, PPP, PP2C

\section{Background}

Osmotic stress, caused by salinity and drought, is one of the major factors limiting plant growth. In order to survive plants have developed numerous defense mechanisms which require diverse signaling pathways for their initiation and regulation, both abscisic acid (ABA)-dependent as well as ABA-independent [1-3].

SnRK2 kinases are key elements in the plant response to osmotic stress and ABA signaling [4-8]. The Arabidopsis

\footnotetext{
* Correspondence: dobrowol@ibb.waw.pl

'Institute of Biochemistry and Biophysics, Polish Academy of Sciences,

Pawińskiego 5a, 02-106 Warsaw, Poland

Full list of author information is available at the end of the article
}

thaliana and Oryza sativa genomes each encode ten members of the SnRK2 family. The kinases (both from Arabidopsis and rice) were expressed in plant protoplasts and their activity was analyzed in response to different treatments. The results revealed that all SnRK2s, except Arabidopsis SnRK2.9, are activated in response to treatment with different osmolytes and some of them additionally in response to ABA $[9,10]$. Based on a phylogenetic analysis SnRK2s have been divided into three groups. This classification overlaps with the discrimination based on their activation by ABA and their role in ABA-dependent and ABA-independent signaling processes. Group 1 consists of kinases which are not activated by exogenous ABA 
in the absence of osmotic stress (further referred to as ABA-non-activated), group 2-those, which are not activated by $A B A$ or activated very weakly, and group 3-strongly activated by ABA $[9,10]$ (Additional file 1: Figure S1). Among the SnRK2 family, the role of kinases from group 3 (Arabidopsis SnRK2.2, SnRK2.3, and SnRK2.6) in the ABA-dependent osmotic stress transduction pathway is best characterized. Together with RCAR/ PYR/PYL (RCAR, regulatory component of ABA receptor/PYR1, pyrabactin resistance 1/PYL, PYR1-like) ABA receptors and clade A PP2C phosphatases, they form the core of the ABA signaling network [11-16]. The kinases are involved in plant defense against water deficit stress and in ABA-dependent plant development. They regulate stress-responsive gene expression and stomatal closure by phosphorylation of various cellular substrates e.g., AREB/ $\mathrm{ABF}$ transcription factors, guard cell ion channels and several others $[17,18]$. Much less is known concerning the role of kinases from the two other groups of SnRK2. Group 2 SnRK2s are involved in drought stress responses $[19,20]$. Although Arabidopsis SnRK2.7 and SnRK2.8 from group 2 were shown to be weakly activated by exogenous $\mathrm{ABA}$, they are considered not to play a physiological role in ABA signaling, or that it is marginal $[4,20]$. Moreover, rice SnRK2s from this group are not activated by ABA [10]. The kinases from group 1 are activated extremely rapidly by high osmoticum-Nicotiana tabacum osmotic stress-activated kinase (NtOSAK, in tobacco) and SnRK2.4 and SnRK2.10 (in Arabidopsis) are fully active as soon as after $1 \mathrm{~min}$ of plant or cell exposure to salt $[21,22]$. SnRK2.4 and SnRK2.10 regulate root growth and its architecture under salinity [22]. The importance of the ABA-non-activated SnRK2s in plant tolerance to water deficit stress was unraveled by a study performed by Fujii et al. [7]. They showed that plants lacking functional kinases from both group 1 and 2 are more affected by osmotic stress than the snrk2.2/2.3/2.6 triple mutant (impaired in ABA-activated SnRK2s), as judged by root growth and fresh weight assessment.

It is well established that reversible phosphorylation of specific Ser/Thr residues in the SnRK2 activation loop is responsible for regulation of SnRK2s' activity [10, 21, 23-25]. Recently Saruhashi et al. [26], showed that a kinase named ARK (for ABA and abiotic stress-responsive Raf-like kinase) acts upstream of SnRK2 in the moss Physcomitrella patens. Additionally, Arabidopsis glycogen synthase kinase 3 (GSK3)-like kinases phosphorylate and enhance the activity of SnRK2.2 and SnRK2.3 in response to ABA [27]. Beside upstream kinases, negative regulators (mainly phosphatases) control SnRK2 activity inside the cell. Some members of clade A PP2C protein phosphatases have been shown to dephosphorylate and in this way inactivate ABA-responsive SnRK2s (from group 3) [28, 29]. The discovery of soluble ABA receptors-RCAR/PYR/PYL-as cellular partners of the clade A PP2Cs [30-35] allowed building of a model of ABA signal transduction with RCAR/PYR/PYL, PP2Cs and SnRK2s forming the core of the signaling network [11-16]. In this model a PP2C phosphatase from clade $\mathrm{A}$ [e.g., ABA-insensitive 1 (ABI1), $\mathrm{ABI}$, hypersensitive to ABA 1 (HAB1) or PP2CA/ABAhypersensitive germination 3 (PP2CA/AHG3)] interacts with an ABA-responsive SnRK2 (from group 3; Arabidopsis SnRK2.2, SnK2.3 and SnRK2.6) independently of $\mathrm{ABA}$ presence. In the absence of ABA, the phosphatase dephosphorylates the SnRK2, keeping it in an inactive form. The situation changes dramatically in stress conditions causing a rise in ABA level. Upon ABA binding RCAR/PYR/PYL undergoes major conformational changes and forms a complex with PP2C, thereby blocking its substrate-binding site. In this way SnRK2 is released from inhibition by PP2C and can be activated $[36,37]$. The mechanism of the SnRK2 activation has been established only for the response to ABA. Some data indicate that also group 2 kinases (Arabidopsis SnRK2.7 and SnRK2.8) can be regulated by group A PP2C phosphatases [28], although their inactivation by those phosphatases has not been proven so far. In the case of the SnRK2s non-activated in response to ABA (group 1), the phosphatases involved in their regulation remain unknown. Clade A PP2Cs have not been considered to be such regulators since no interaction between SnRK2.10 (SnRK2 from group 1) and the phosphatases could be detected in yeast two-hybrid assays $[25,28]$, and the kinase activation in response to osmotic stress was the same in Arabidopsis PP2C mutants and wild type plants [25]. However, structural and some in vitro studies have not excluded the possibility that clade A PP2Cs could in principle dephosphorylate ABA-unresponsive SnRK2s [38].

Here, we describe studies undertaken to identify the phosphatases(s) regulating the activity of ABA-nonactivated SnRK2s represented by Arabidopsis SnRK2.4 kinase. Our results show that ABI1, a member of the PP2C family, interacts with and inhibits SnRK2.4 in plant cells. Additionally, we show that SnRK2s, at least those that are not activated in response to ABA (from group 1), are inhibited in plant cells by okadaic acidsensitive phosphatases from the PPP family.

\section{Results}

Analysis of interactions between Arabidopsis clade A PP2C phosphatases and SnRK2 kinases

Nicotiana tabacum osmotic stress-activated kinase (NtOSAK, GenBank: AAL89456) is a member of group 1 of the SnRK2 family, exhibiting highest sequence similarity to SnRK2.4 [TAIR: At1g10940] and SnRK2.10 [TAIR: At1g60940] in Arabidopsis ([39] and Additional file 1). Our studies indicated that NtOSAK activity is regulated 
by phosphorylation $[21,40]$, and the kinase is inactivated in vitro by dephosphorylation catalyzed by $\mathrm{NtPP} 2 \mathrm{C} 2$ [GenBank: AB110956] phosphatase, member of the clade A of the PP2C family (Additional file 2). NtPP2C2 dephosphorylates specifically Ser154 and S158, whose phosphorylation is crucial for the kinase activity (Additional files 2 and 7 and [21]). These results suggested that clade A PP2Cs could regulate not only the ABA-activated but also other types of SnRK2s. Moreover, supplemental materials presented by Nishimura et al. [41] showed several peptides of SnRK2.4 and also of other SnRK2s from group 1 among peptides of proteins co-immunoprecipitating with ABI1 [TAIR: At4g26080], a PP2C clade A phosphatase.

Therefore, using the yeast two-hybrid (YTH) system, we looked for interactions between ABA-non-activated SnRK2s, SnRK2.4 and SnRK2.10, which exhibit highest sequence similarity to NtOSAK (Additional file 1), and Arabidopsis PP2C clade A phosphatases. Additionally, to compare our results with published data, we assayed SnRK2s whose binding with PP2Cs had already been established-SnRK2.8 [TAIR: At1g78290] (from group 2) and SnRK2.6 [TAIR: At4g33950] (from group 3). Our results largely confirmed the previously published data $[25,28]$. In our hands SnRK2.8 interacted in a clear-cut manner with two phosphatases, ABI1 and PP2CA [TAIR: At3g11410], and weakly with ABI2 [TAIR: At5g57050] (Fig. 1a). Similarly to data presented by Umezawa et al. [28] and Vlad et al. [25] we did not see an interaction of SnRK2.10 (from group 1) with any of the phosphatases studied. However, for SnRK2.4, we did observe reproducible interaction with one of the phosphatases, ABI1 (Fig. 1a). The interaction was weaker than that observed for SnRK2.6 or SnRK2.8; the growth of yeast expressing SnRK2.4 in fusion with the Gal4 DNA-binding domain and ABI1 in fusion with the activation domain was abolished on medium supplemented with aminotriazole at concentration higher than $4 \mathrm{mM}$.

To verify the observed interaction between ABI1 and SnRK2.4 in vitro pull-down assays were performed. Recombinant glutathione-sepharose-bound ABI1 in fusion with GST, or GST alone (as a negative control) were used as bait. The presence of bound SnRK2.4 was analyzed by immunoblotting using antibodies against the N-terminal peptide specific for SnRK2.4 and SnRK2.10 (anti-SnRK2.4/SnRK2.10). As shown in Fig. 1b SnRK2.4 interacted with ABI1 in the pull-down assay.

\section{ABI1 interacts with SnRK2.4 in planta}

To investigate whether the interaction between SnRK2.4 and ABI1 takes place in planta we resorted to the bimolecular fluorescence complementation (BiFC) approach. Additionally, we tested the interaction between ABI1 and SnRK2.8, which had never been studied for SnRK2 kinases from group 2 in plant cells. SnRK2.4 or
SnRK2.8 or SnRK2.6 (as a positive control) together with ABI1, each fused to complementary non-fluorescent fragments of YFP, were transiently produced in Arabidopsis protoplasts. We observed interactions between ABI1 and all the kinases studied both in the nucleus and in the cytoplasm (Fig. 2).

\section{ABI1 dephosphorylates and inhibits SnRK2.4 activity both in vitro and in plant cells}

In order to check whether ABI1 is able to regulate SnRK2.4 we analyzed the effect of the recombinant phosphatase on the kinase activity. In parallel, to evaluate the impact of a phosphatase from a group other than clade A PP2C on SnRK2.4 in these conditions, AP2C3 [TAIR: At2g40180], a clade B PP2C, was also assayed. The specific activity of the recombinant phosphatases was estimated using a commercial phosphatase activity assay (Additional file 3). Equal amounts of activity of each of the phosphatases were then used in in vitro assays against SnRK2.4 as substrate. ABI1 inhibited the kinase (Fig. 3a) and significantly reduced phosphorylation of Ser-158, a conserved residue in the activation loop of SnRK2s, phosphorylation of which is crucial for their activity [21, 23, 24]. In contrast, AP2C3 did not affect the phosphorylation status of Ser-158 or the kinase activity. Additionally, the effect of ABI1 on SnRK2.8 (from group 2) and SnRK2.6 (from group 3, as a positive control) was studied. The phosphatase dephosphorylated and inhibited the kinases (Fig. 3a). GST alone had no influence on the activity of the SnRK2s studied (Additional file 4). The results suggested that ABI1 is the regulator of various SnRK2 kinases, including the ABA-nonactivated ones.

In order to investigate whether ABI1 dephosphorylates and inactivates SnRK2.4 in planta the kinase, in fusion with EGFP, was transiently expressed alone or coexpressed with c-Myc-ABI1 in Arabidopsis protoplasts. Transformed protoplasts were subjected to salinity stress (300 $\mathrm{mM} \mathrm{NaCl}$ ) for $20 \mathrm{~min}$ and the activity of the kinase was monitored by in-gel kinase assay. This experiment revealed that ABI1 inactivates SnRK2.4 in planta (Fig. 3b). Similarly, co-expression of ABI1 with SnRK2.8 caused inhibition of the kinase activity under salt stress (Fig. 3b).

We also monitored the activity of ABA-non-activated SnRK2 kinases in Arabidopsis T87 cells expressing StrepTag-ABI1 [42]. The cells were treated with $500 \mathrm{mM}$ $\mathrm{NaCl}$ for various times and the activity of SnRK2s immunoprecipitated using anti-SnRK2.4/SnRK2.10 antibodies was monitored. Due to the specificity of the antibodies used, both SnRK2.4 and SnRK2.10 were immunoprecipitated from the cell extracts. As a consequence, their combined activity was analyzed, since they cannot be distinguished after SDS-PAGE separation. The salt-induced SnRK2.4/ SnRK2.10 activity was significantly lowered (nearly 


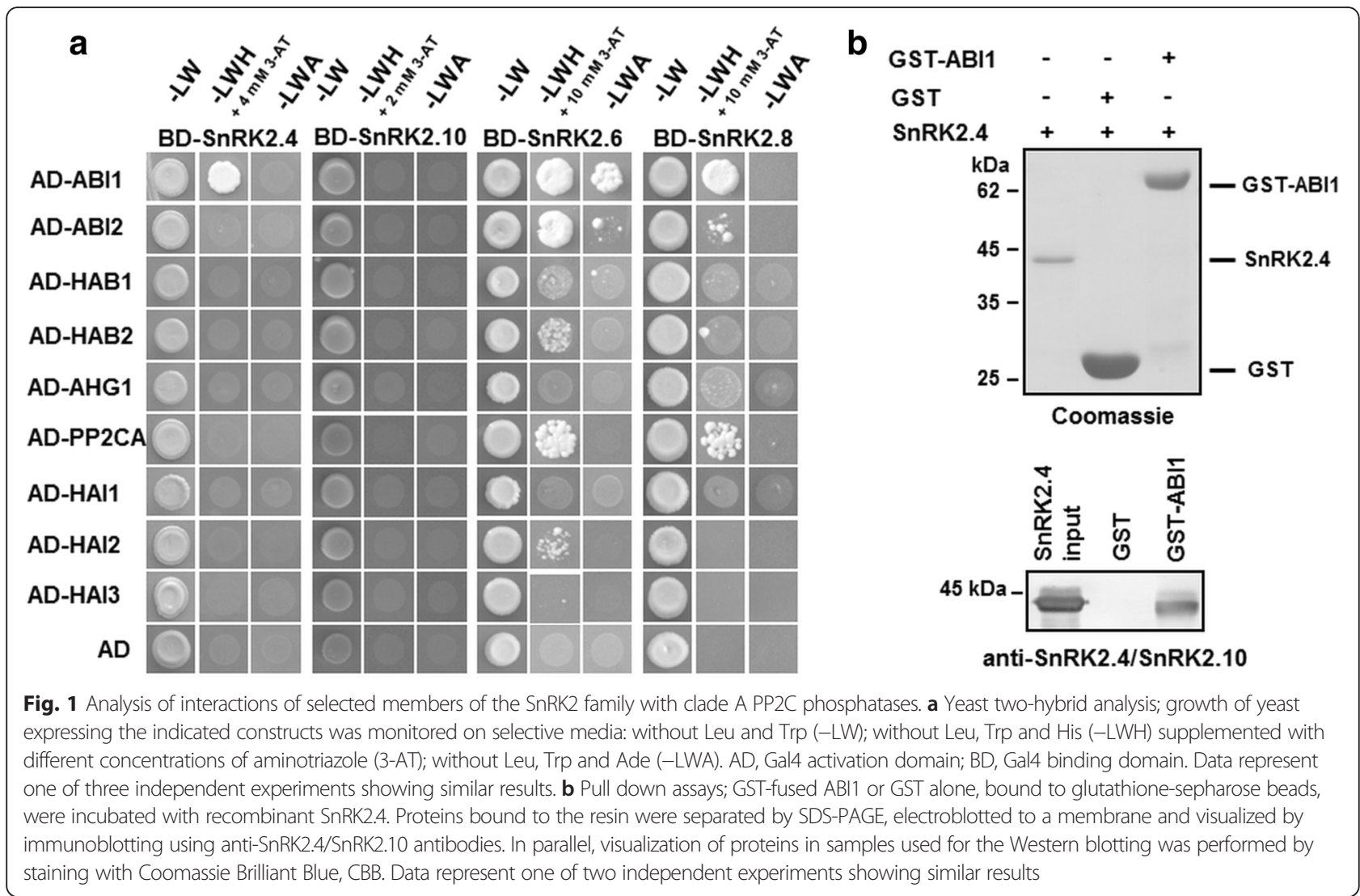

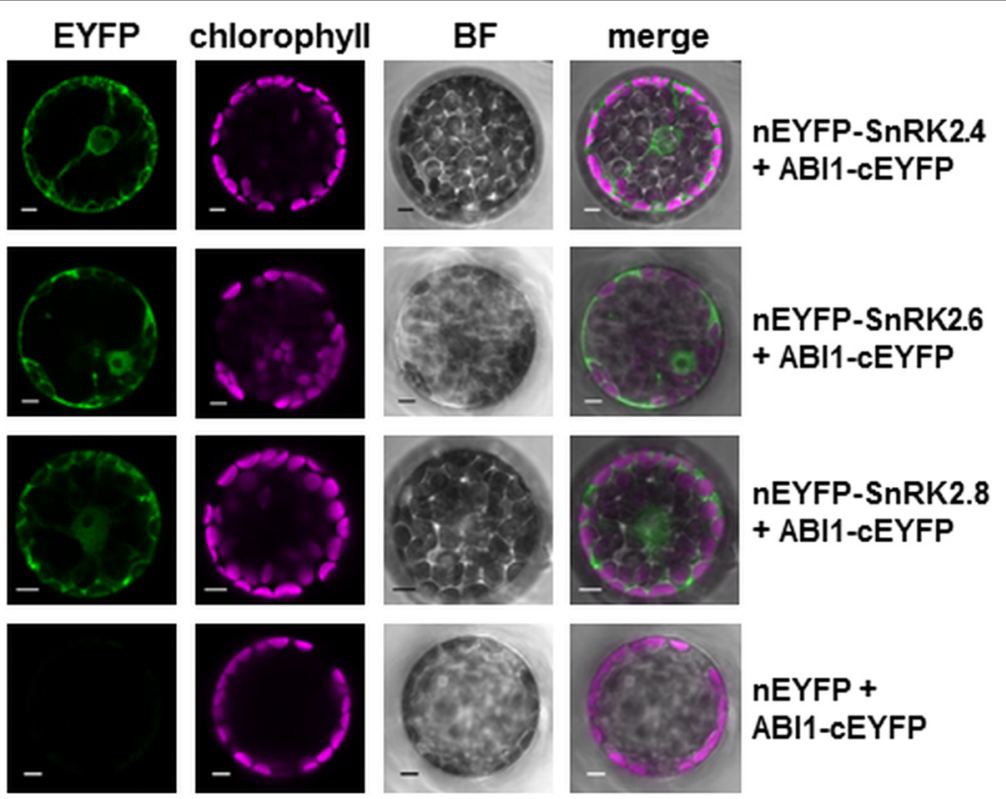

Fig. 2 ABI1 interacts with SnRK2.4 in planta. Interaction of the proteins was analyzed by BiFC assay. Protoplasts isolated from Arabidopsis leaves were transiently co-transformed with pairs of plasmids encoding: ABI1-cEYFP and nEYFP-SnRK2.4 or ABI1-cEYFP and nEYFP-SnRK2.8 Positive control of the BiFC assay is provided by the ABI1-CEYFP/nEYFP-SnRK2.6 interaction. For negative control, cEYFP-ABI1 was co-expressed with nEYFP. Scale bar $=10 \mu \mathrm{m}$; BF, bright field. Data represent one of three independent experiments showing similar results 


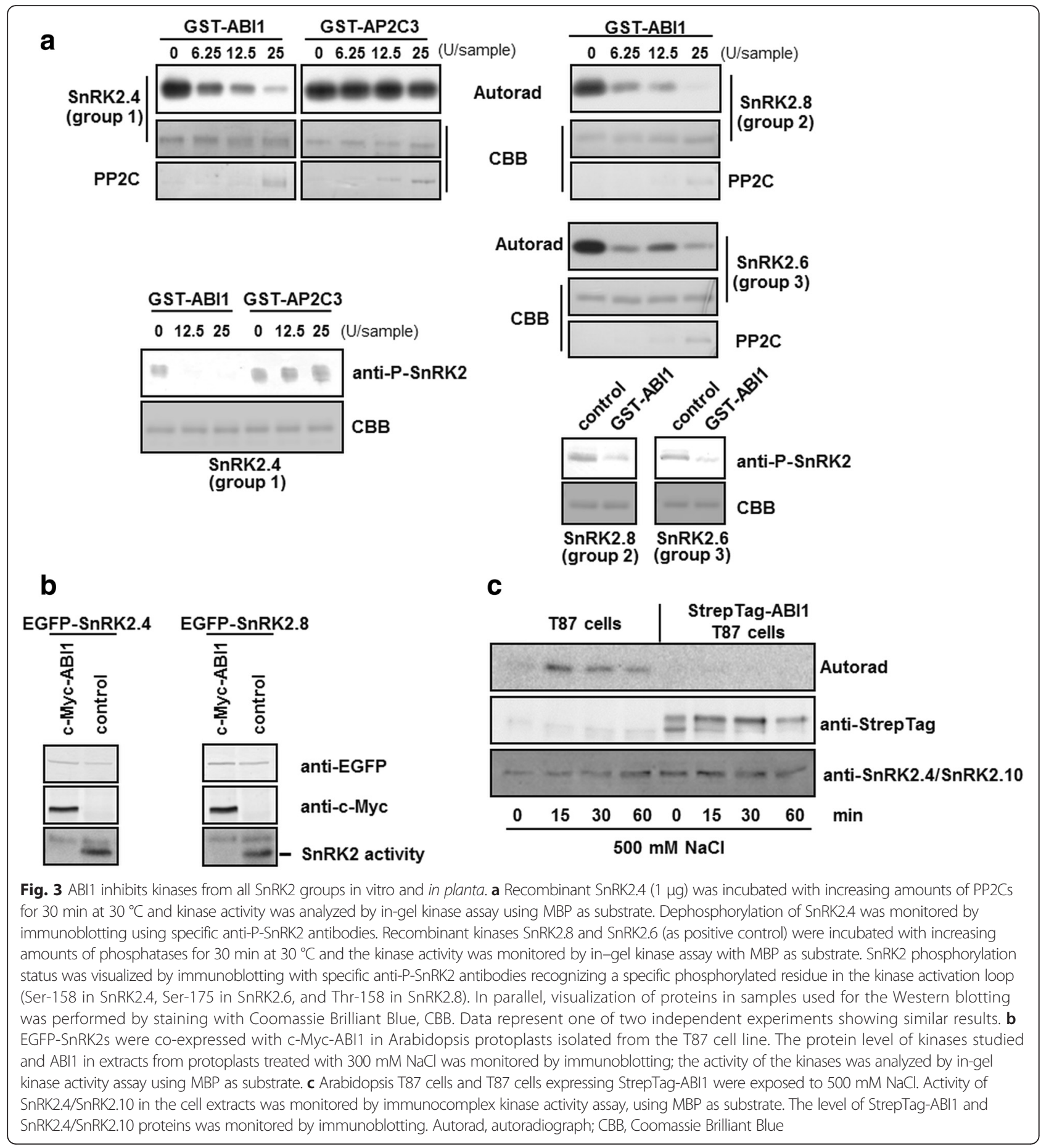

undetectable) in cells expressing StrepTag-ABI1 in comparison to control T87 cells (Fig. 3c).

\section{Knockout insertion mutant abiltd exhibits opposite} phenotype to snrk2.4 in primary root growth of seedlings exposed to salinity stress

In order to analyze physiological consequences of the regulation of SnRK2.4 activity by ABI1 phosphatase we compared phenotypes of plants with altered SnRK2.4 or ABI1 levels. As it was mentioned before SnRK2.4 and SnRK2.10 are involved in the regulation of root architecture in plants exposed to salinity stress; the primary root (PR) length of the snrk2.4 mutant exposed to $115 \mathrm{mM}$ $\mathrm{NaCl}$ is significantly shorter in comparison to wild type seedlings [22]. To check whether ABI1 is involved in the plant response to salinity we analyzed the phenotypes of 
abiltd, a mutant with T-DNA insertion in $A B I 1$, and in parallel the snrk2.4 mutant and wild type Col-0 (WT) plants. We compared the PR length of seedlings exposed to $115 \mathrm{mM} \mathrm{NaCl}$ (and also in control conditions). In our hands, in control conditions the roots of snrk2.4 were shorter than those of the WT plants or the abiltd mutant (Fig. 4a and b). After stress application, the PRs of the snrk2.4 mutant and WT seedlings grown on medium with salt were significantly shorter than the controls. However, the roots of snrk2.4 were the most affected by salt, exhibiting the most severe root growth inhibition (Additional file 5 ) and being approximately $65 \%$ shorter than the roots of WT seedlings. In contrast, the roots of the abiltd mutant were significantly longer in comparison to WT, by $40 \%$ (Fig. 4a and b), indicating that ABI1 is involved in the regulation of root growth under salinity stress.

\section{Group 1 SnRK2s are regulated by okadaic acid-sensitive phosphatase(s)}

Our previous results showed that the catalytic subunit of maize phosphatase PP2A can dephosphorylate and inactivate NtOSAK [40]. Therefore, in order to test if
SnRK2.4 could be regulated by phosphatases other than PP2Cs in plant cells, we monitored SnRK2.4/SnRK2.10 activity in Arabidopsis T87 cells exposed to okadaic acid (OA), an inhibitor of the PPP family of serine/ threonine-specific phosphoprotein phosphatases (e.g., PP1 and PP2A) [43]. T87 cells were pretreated with $0.2 \mu \mathrm{M}$ or $1 \mu \mathrm{M}$ OA (or with the OA solvent only as a control) for $2 \mathrm{~h}$ and then exposed to $500 \mathrm{mM} \mathrm{NaCl}$. SnRK2.4/SnRK2.10 activity in cells exposed to such treatment was measured by immunocomplex kinase activity assay. The results showed significantly higher SnRK2.4/SnRK2.10 activity in cells pretreated with OA in comparison to control, indicating that also OAsensitive phosphatases limit the salinity-induced SnRK2 activity (Fig. 5).

\section{Discussion}

SnRK2 kinases, especially those from group 1, are rapidly and transiently activated during the plant response to salinity stress or water deficit [19, 21, 22, 40, 44]. In contrast to the well-studied ABA-activated SnRK2s (group 3), the mode of regulation of SnRK2s from group 1 is unknown. We have shown that some members of

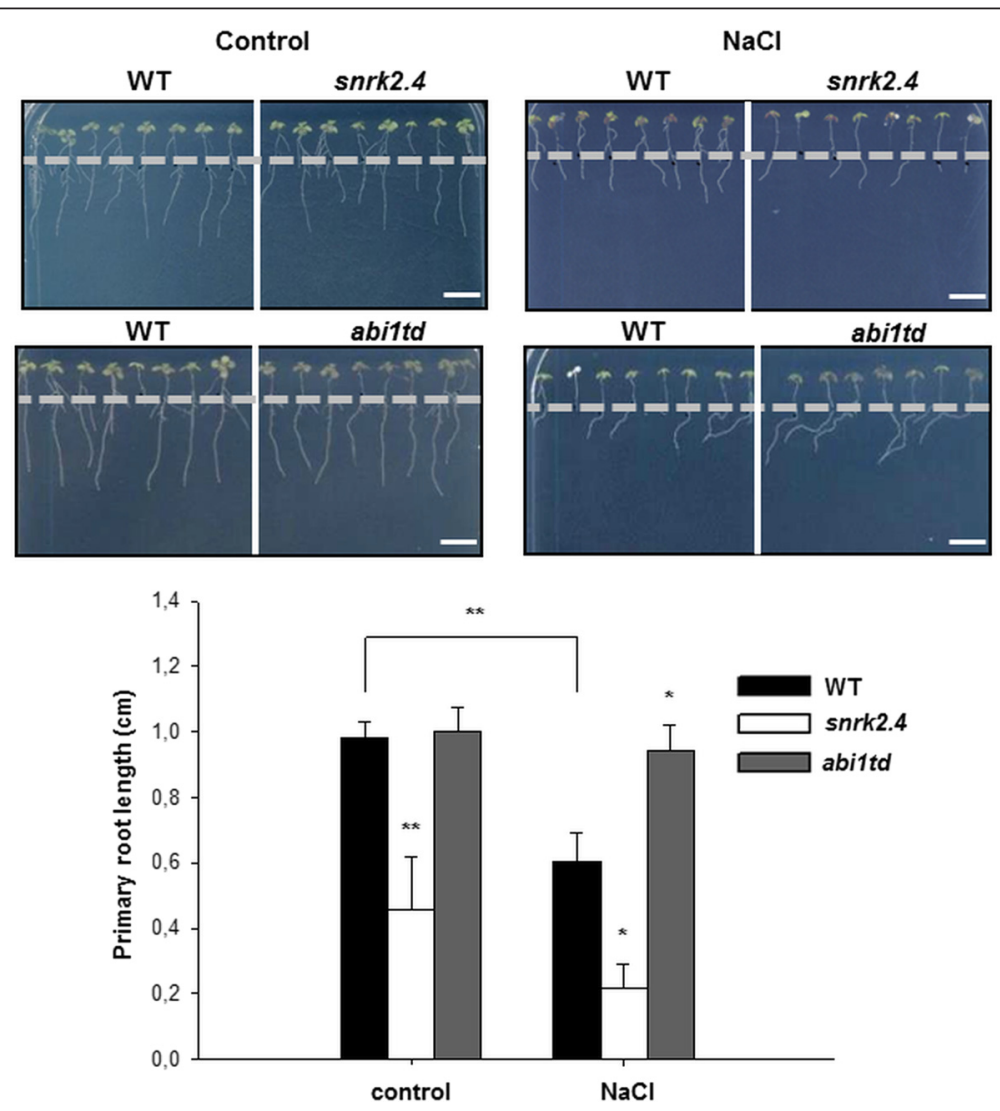

Fig. 4 ABI1 negatively regulates root elongation under salt stress. Seven-day-old seedlings grown vertically on $1 / 2$ MS media were transferred into square Petri plates with control media or $115 \mathrm{mM} \mathrm{NaCl}$ and the increase in primary root length was measured. Dotted line shows the approximate length of roots just after transfer. The graphs present mean values $( \pm \mathrm{SE}), \mathrm{n}=7$. Statistical analysis was done by $t$-test; bar on photographs $=0.5 \mathrm{~cm}$ 


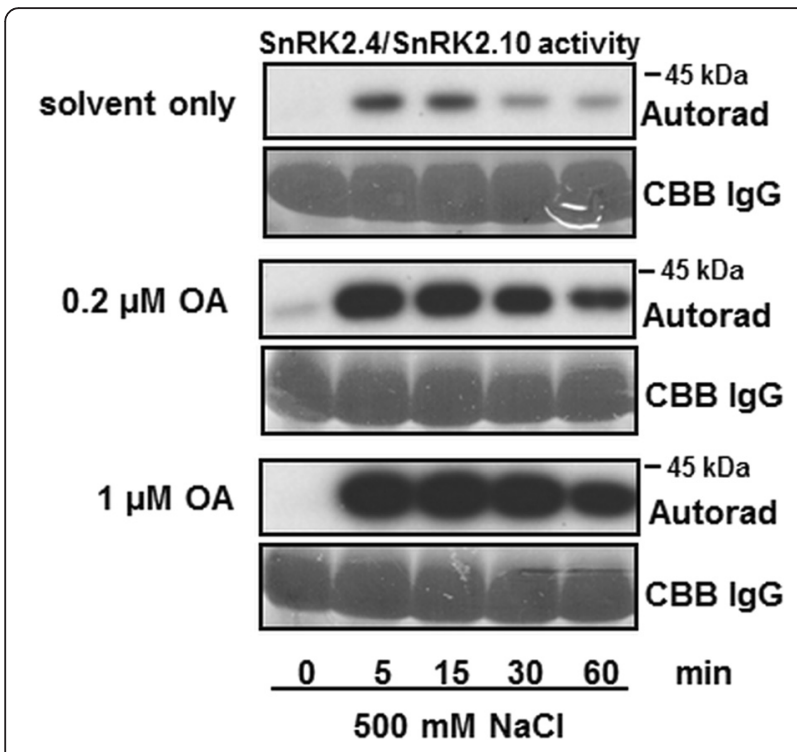

Fig. 5 Pretreatment of T87 cells with OA enhances the salinity-induced activity of ABA-non-activated SnRK2s. Arabidopsis T87 cells were preincubated with indicated concentrations of OA for $2 \mathrm{~h}$, followed by exposure to salinity stress. SnRK2.4/SnRK2.10 activity in cell extracts was monitored by immuno-in-gel kinase activity assay, using MBP as substrate and anti-SnRK2.4/SnRK2.10 antibodies. The level of IgG is presented as loading control. CBB, Coomassie Brilliant Blue. Data represent one of two independent experiments showing similar results

group 1 are inhibited by clade A PP2C phosphatases. This result was intriguing for several reasons. First, no interaction between SnRK2.10 (SnRK2 from group 1, with high sequence similarity to SnRK2.4) and these phosphatases could be detected previously [25, 28]. Second, SnRK2.10 activation in response to osmotic stress was similar in Arabidopsis $p p 2 c$ mutants and wild type plants [25]. Finally, group $1 \mathrm{SnRK} 2 \mathrm{~s}$ are not involved in a direct ABAdependent pathway, induced by ABA application $[9,24]$, in contrast to the current paradigm for clade A PP2Cs. To elucidate the regulation of group 1 SnRK2s, we took advantage of our previous unpublished data indicating that NtOSAK, the tobacco kinase, member of group 1 of the SnRK2 family, can be dephosphorylated and inactivated by NtPP2C2 (clade A PP2C from tobacco) and data mining in Nishimura et al. [41] showing coimmunoprecipitation of group 1 SnRK2s and ABI1. Next, we showed that SnRK2.4 interacts with ABI1 and is dephosphorylated and inhibited in vitro by the phosphatase, similarly to SnRK2.8 (group 2) and the ABAactivated SnRK2.6 (group 3). This probably reflects the fact that the catalytic domains (including activation loops) of all SnRK2s are nearly identical. Analysis of structures of the SnRK2.6-HAB1 [37] and SnRK2.6ABI1 [45] complexes has revealed that the phosphatase and kinase active sites form the major binding interface, with three distinct regions in the kinase domain contributing to the kinase - phosphatase interaction. All the residues crucial for the complex formation with the phosphatases are also conserved in the SnRK2s from group 1. The C-terminal part ("Domain II", specific for ABA-activated SnRK2s) seems to be involved mainly in complex stabilization.

Our results showed that inhibition of SnRK2.4 by ABI1 occurs both in vitro and in planta. In plant protoplast and in Arabidopsis T87 cells overexpressing ABI1 the activity of SnRK2.4 (or SnRK2.4/SnRK2.10 in plant cells) is significantly lower than in cells/protoplasts without the phosphatase overexpression. Moreover, we showed that ABI1 plays an opposite role to SnRK2.4 in regulation of primary root (PR) growth under salinity stress; SnRK2.4 is involved in positive regulation of PR growth of plants exposed to salinity [22], whereas ABI1 in negative regulation, according to our results presented here.

There are several data indicating an ABA-independent mechanism of PR growth regulation under salt stress conditions. Duan et al. [46] showed that $\mathrm{NaCl}$ shock significantly activated ABA signaling only in lateral roots (LRs) and not in PRs. Moreover, they showed that PR growth was similarly affected by salt in mutants of ABA synthesis and ABA signaling as in WT plants, in contrast to the growth inhibition of LRs. These facts, as well as data presented by McLoughlin et al. [22] and our results point to the involvement of SnRK2.4 and ABI1 in an ABAindependent pathway regulating PR growth under salinity. However, we cannot rule out the possibility that ABI1 regulates root growth under salt stress also through dephosphorylation of other proteins. It should be kept in mind that clade A PP2Cs have many more targets. They interact also with calcium dependent protein kinases, CPKs $[47,48]$, and with several other proteins, among them downstream elements of SnRKs and CPKs (e.g., transcription factors [47]). The fact that clade A PP2Cs regulate various signaling pathways in plants at multiple levels indicates that they constitute a hub in the cross talk between ABA-dependent and ABA-independent stress and development signaling pathways in plants.

Numerous targets of clade A PP2Cs and their functional redundancy make the studies on their role in the regulation of particular protein kinases in physiological context challenging. Moreover, the question still remains of how the activity of the phosphatases is regulated in response to various environmental stresses not involving a direct increase in ABA level. So far, PYR/PYL/RCAR $\mathrm{ABA}$ receptors are known to regulate the activity of clade A PP2Cs in response to ABA. It was proposed that the phosphatase activity is also inhibited by their interaction with certain PYR/PYL/RCAR receptors in an ABA-independent manner [49]. Particularly, PYL10 was reported to inhibit $\mathrm{PP} 2 \mathrm{C}$ activity in an ABAindependent manner. However, this result has been 
recently refuted by Li et al. [50], who demonstrated that PYL10 activity is ABA-dependent. Moreover, when phosphorylated protein substrates (not small phosphopeptides) have been tested as substrates of PP2Cs, followed by direct analysis of their phosphorylation status, no substantial ABA-independent inhibition by ABA receptors could be found [51, 52]. Data published by Vlad et al. [25] indicate that in response to osmotic stress SnRK2.6 can be regulated by clade A PP2Cs, since kinase activity was notably increased in a hab1-1 abi1-2 abi2-2 triple loss-of-function mutant compared to wild type. However, activation of SnRK2.6 by osmotic stress occurred in ABA-insensitive mutants carrying specific PP2C mutations that make them refractory to inhibition by PYR/PYL/RCAR proteins [25]. This suggests that ABA receptors are rather not involved in the negative regulation of the $\mathrm{PP} 2 \mathrm{Cs}$ in response to osmotic stress. Possibly, other cellular partners of PP2Cs exist which inhibit their activity in an ABA-independent manner. One example of such proteins are calcineurin B-like proteins (CBLs). Lan et al. [53] showed that some CBLs interact with and inhibit PP2CA and in this way restore the activity of CBL-interacting protein kinase 6 (CIPK6) and the CIPK6-dependent activation of the $\mathrm{K}^{+}$inward rectifying channel AKT1 in plant cells. Nevertheless, extensive studies are needed to elucidate the mechanism triggering the ABA-independent inhibition of PP2C phosphatases in response to osmotic stress. Not only proteins can be considered as potential inhibitors of phosphatases in response to osmotic stress. Very tempting is the idea that the phosphatases involved in the regulation of the SnRK2 family members are inactivated by various second messengers produced transiently in early steps of stress response, e.g., reactive oxygen species (ROS), phosphatidic acid (PA), or nitric oxide (NO). It has been shown that PA and ROS inhibit some of PP2Cs [54-56]. However, there are data showing that reagents inducing oxidative stress [57] and S-nitrosylation [58] also inhibit SnRK2s. Since $\mathrm{NO}$ and ROS can regulate phosphatases as well as kinases, signal transduction most probably relies on timing and strength of the signal.

Moreover, we cannot exclude the possibility that, in contrast to a fast response, SnRK2s from group $1 \mathrm{might}$ be involved in ABA-dependent signaling in sustained stress conditions and that other PP2Cs are also involved in regulation of kinases from group 1 of the SnRK2 family.

Additionally, our results show that apart from PP2Cs, the activity of SnRK2.4/SnRK2.10 seems likely to be regulated by OA-sensitive Ser/Thr phosphoprotein phosphatases from the PPP family. SnRK2s belong to the AMPK/SNF1 family. The activity of mammalian AMP-activated protein kinase (AMPK) and yeast sucrose non-fermenting 1 (SNF1) kinase is negatively regulated by several protein phosphatases: type 2A (PP2A),
PP1, and PP2C [59-63]. Numerous reports link plant PPPs with osmotic stress signaling and defense responses [64-71]. The published data suggest that the phosphatases can play both positive and negative roles in osmotic stress and ABA signal transduction. Recently it was shown that several PP2A regulatory subunits interact with SnRK2.6/OST1, as well as with other ABA-activated SnRK2s [72]. Surprisingly, the authors did not observe any significant cross-regulation of PP2A and SnRK2 activity in plants exposed to ABA. Moreover, while this paper was under revision, Hou et al. [73] showed that Type One Protein Phosphatase 1 (TOPP1) and its regulatory protein, At Inhibitor-2 (AtI-2), negatively regulate ABA-activated SnRK2s and subsequently ABA signaling. It is challenging to determine which PPP phosphatase(s) is involved in the regulation of ABA-non-activated SnRK2s in response to osmotic stress, first of all because of the scarce information on the physiological roles of these phosphatases, but also because of their complexity. The plant PPP family comprises of PP1, PP2A, PP4, PP5, PP6, PP7, Kelch-like repeat domain (PPKLs) and Shewanella-like protein (SLP) phosphatases (for review see Uhrig et al., [74]); OA affects all of them except SLPs. The PP2A holoenzyme consists of three types of subunits-catalytic (C), scaffolding/regulatory (A), and regulatory (B), of which five, three and seventeen isoforms, respectively, have been identified in Arabidopsis. They form different holoenzymes with divergent functions. Several regulatory subunits have also been identified for PP4 and PP6. Interestingly, the PP6 phosphatase catalytic subunits can interact with RCN1 (roots curl in n-naphthylphthalamic acid 1), a regulatory subunit of PP2A [75], which makes the PPP regulation even more complicated. Similar complexity also concerns PP1 phosphatases; there are nine PP1s in Arabidopsis, and numerous regulatory subunits. Identification of phosphatases belonging to the PPP family, which are involved in the inhibition of ABA-nonactivated SnRK2s, is currently under investigation in our laboratory.

\section{Conclusions}

Our results revealed that ABI1 plays a wide role in SnRK2s regulation, inhibiting not only the ABAactivated members of the family, but also SnRK2.4, a kinase not activated in response to ABA. Moreover, it seems that ABI1 is not the only phosphatase, which regulates the activity of SnRK2s activated by osmotic stress in an ABA-independent manner; members of the PPP family are also involved in such regulation. It remains to be investigated how ABI1 and also other SnRK2 phosphatases are inhibited in response to osmotic stress independently of ABA to allow transient SnRK2 activation. 


\section{Methods}

\section{Plant material and growth conditions}

Arabidopsis thaliana lines used: ecotype Col-0 - wild type; T-DNA insertion lines: abiltd (corresponding to abi1-3) (SALK_076309, [76]) and snrk2.4 (SALK_080588, [22]). Seeds were sterilized as described in Kulik et al. [77]. Plants were grown as described in McLoughlin et al. [22]. Arabidopsis T87 cells were maintained as described by Yamada et al. [78] and treated with $500 \mathrm{mM} \mathrm{NaCl}$ six days after subculturing. For okadaic acid (OA) treatment cells were preincubated with $0.2 \mu \mathrm{M}$ or $1 \mu \mathrm{M}$ OA (Enzo Life Sciences, www.enzolifesciences.com) or $0.8 \%$ ethanol as control for $2 \mathrm{~h}$ and then treated with $500 \mathrm{mM} \mathrm{NaCl}$ for indicated time.

Root growth assay was performed as described in McLoughlin et al. [22]. Change in root length was determined using the ImageJ software (http://imagej.nih.gov/ij/). $T$-test performed in Sigma Plot for Windows Version 13.0 software was applied for statistical analysis.

\section{Yeast two-hybrid interaction assays}

Construction of pGBT9 plasmids with cDNA of SnRK2.4, SnRK2.6 and SnRK2.8 was described previously [79]. The cDNA encoding SnRK2.10 or PP2C phosphatases were cloned into pGBT9 or pGAD424 (Clontech, www.clontech.com), respectively, primers used are listed in Additional file 6. The AH109 yeast strain was transformed according to [80]. Transformants were selected on SD medium without Leu/Trp and then assayed on SD medium without Leu/Trp/His supplemented with $1 \mathrm{mM}-10 \mathrm{mM}$ of aminotriazole (3-AT) or SD without Leu/Trp/Ade.

\section{Expression and purification of recombinant proteins}

Recombinant SnRK2.4, SnRK2.6 and SnRK2.8 were prepared as described previously [79]. Plasmid encoding ABI1 was obtained by PCR amplification of cDNA of $\mathrm{ABI} 1$ and its insertion into the pGEX-4 T-1 vector (GE Healthcare, www.gelifesciences.com). The pGEX-AP2C3 plasmid [81] was kindly provided by Dr. Irute Meskiene (Max F. Perutz Laboratories, University of Vienna). Recombinant PP2Cs were produced in E. coli Rosetta (Novagen) at $37{ }^{\circ} \mathrm{C}$ for $2 \mathrm{~h}$ and purified according to Frangioni et al. [82].

\section{Preparation of plant protein extracts}

Protein extracts were prepared as described previously [77].

\section{Immunoblot analysis}

Antibodies used: anti-SnRK2.4/SnRK2.10 (previously named anti-NtOSAK/SnRK2.4/SnRK2.10), described in Kulik et al. [77], and anti-P-SnRK2 phospho-specific polyclonal raised against the phosphopeptide KS(P)TVGT) (BioGenes $\mathrm{GmbH}$, www.biogenes.de), described in Burza et al. [21]; anti-GFP (Molecular Probes, www.thermofisher.com); anti-c-Myc (Santa Cruz Biotechnology, www.scbt.com); StrepMAB-Classic, HRP conjugate (IBA $\mathrm{GmbH}$, www.iba-lifesciences.com). Western blotting with anti-P-SnRK2 and anti-SnRK2.4/SnRK2.10 antibodies was performed as described previously [21, 77], whereas for anti-GFP, anti-c-Myc and anti-StrepTag as indicated by the manufacturers.

\section{Immunoprecipitation}

Immunoprecipitation was performed as described previously [77], with minor modifications. For every $\mathrm{mg}$ of protein from crude extract $50 \mu \mathrm{L}$ of protein A-agarose slurry (Santa Cruz Biotechnology, www.scbt.com) and $100 \mu \mathrm{g}$ of antibodies was used. For analysis of SnRK2.4/ SnRK2.10 activity immunoprecipitation was performed from $500 \mu \mathrm{g}$ of crude protein extract.

\section{In-gel kinase assay}

In-gel kinase activity assays were performed according to Zhang and Klessig [83].

\section{In vitro phosphatase assays}

In vitro dephosphorylation assays with SnRK2s as substrates were performed in buffer containing $20 \mathrm{mM}$ Tris- $\mathrm{HCl}, \mathrm{pH} 7.5$ and $25 \mathrm{mM} \mathrm{MgCl}_{2}$ (final volume $25 \mu \mathrm{L}$ ), for $30 \mathrm{~min}$ at $30{ }^{\circ} \mathrm{C}$. Reactions were stopped by addition of Laemmli sample buffer and boiling for $2 \mathrm{~min}$. Specific activity of recombinant phosphatases was determined using the Serine/Threonine Phosphatase Assay System (Promega, www.promega.com) and activity units (U) were calculated for each phosphatase, where one $U$ is the amount of phosphatase, which releases 1 picomole of phosphate per minute.

\section{In vitro binding assay}

Glutathione-Sepharose 4B beads $(20 \mu \mathrm{L})$ (GE Healthcare, www.gelifesciences.com) with bound GST-ABI1 or GST were incubated with $10 \mu \mathrm{g}$ of recombinant SnRK2.4 in binding buffer (50 mM Tris- $\mathrm{HCl}, \mathrm{pH} 8.0,50 \mathrm{mM} \mathrm{NaCl}$, $0.01 \%$ Triton X-100, $40 \mathrm{mM}$ DTT and 1x Complete Protease Inhibitor Cocktail Roche, Sigma-Aldrich, www.sigmaaldrich.com) in a final volume of $100 \mu \mathrm{L}$. After $45 \mathrm{~min}$ of shaking at RT the beads were washed 5 times with the binding buffer. Proteins attached to the resin were separated by SDS-PAGE, and either visualized by Coomassie staining, or transferred onto PVDF membrane and visualized by immunoblotting with antiSnRK2.4/SnRK2.10 antibodies.

\section{Protoplast transient expression assay}

For expression of proteins in protoplasts followed by analysis of enzyme activity, pSAT vectors were used [84]. Construction of pSAT6-EGFP-C1 plasmids with cDNA 
of SnRK2.4 and SnRK2.8 was described previously [79]. For generation of c-Myc-ABI1 the cDNA encoding the phosphatase was cloned into a modified pSAT6-MCS vector, with the c-Myc coding sequence introduced between the NcoI and BglII sites. Protoplasts from T87 cells were isolated and transformed as described previously [79]. Constructs for BiFC assays were prepared using the Gateway ${ }^{\circ}$ Cloning system (Invitrogen, www.thermofisher.com). ABI1, SnRK2.4, SnRK2.6 and SnRK2.8 cDNAs were PCR amplified and cloned into the pENTR $^{\circ}-\mathrm{D} / \mathrm{TOPO}^{\mathrm{in}}$ vector. Next, the cDNAs were introduced into pSITE II n-EYFP-N1 or pSITE II cEYFP-C1 vectors [85] by Gateway LR reaction. Protoplasts from leaves of 5-week-old Arabidopsis Col-0 plants were isolated and transformed according to [86]. Approximately $1 \times 10^{6}$ protoplasts were transfected with $40 \mu \mathrm{g}$ of plasmid DNA, $20 \mu \mathrm{g}$ of each plasmid. Sixteen hours after transformation YFP signal was visualized by confocal microscopy as described previously [79] or the protoplasts were treated with $300 \mathrm{mM} \mathrm{NaCl}$ for time indicated in Results.

\section{Remaining accession numbers}

Sequence data for the following can be found in the TAIR database: HAB1, At1g72770; HAB2, At1g17550; AHG1, At5g51760; HAI1, At5g59220; HAI2, At1g07430; HAI3, At2g29380.

\section{Additional files}

Additional file 1: Figure S1. Phylogenetic tree of Arabidopsis (SnRK2.1 to SnRK2.10), rice (SAPK1 to SAPK10) SnRK2s, and tobacco SnRK2 (NtOSAK). (PDF $427 \mathrm{~kb}$ )

Additional file 2: Figure S2. Inhibition of NtOSAK activity by GST-NtPP2C2 is correlated with dephosphorylation of Ser-154 and Ser-158 in the kinase activation loop. (PDF $683 \mathrm{~kb}$ )

Additional file 3: Figure S3. Activity of recombinant PP2Cs used in this study. (PDF $165 \mathrm{~kb}$ )

Additional file 4: Figure S4. GST does not affect SnRK2 kinase activity in in vitro assay. (PDF $251 \mathrm{~kb}$ )

Additional file 5: figure S5. Primary root growth inhibition of studied plant lines under salt stress. (PDF $229 \mathrm{~kb}$ )

Additional file 6: Table S1. PCR primers used for cloning. (DOC $53 \mathrm{~kb}$ ) Additional file 7: Supporting Methods. (DOC $34 \mathrm{~kb}$ )

\section{Abbreviations}

ABA, abscisic acid; ABl1, ABA-insensitive 1; AHG3, ABA-hypersensitive germination 3; AMPK, AMP-activated protein kinase; ARK, ABA and abiotic stress-responsive Raf-like kinase; Atl-2, At inhibitor-2; BiFC, bimolecular fluorescence complementation; CBL, calcineurin B-like proteins; CIPK, CBL-interacting protein kinase; $C P K$, calcium-dependent protein kinase; GSK3, glycogen synthase kinase 3; $H A B 1$, hypersensitive to $A B A 1$; $L R$, lateral root; $N O$, nitric oxide; NtOSAK, Nicotiana tabacum osmotic stress-activated kinase; OA, okadaic acid; PA, phosphatidic acid; PP2C, phosphoprotein phosphatase 2C; PPKL, Kelch-like repeat domain; PPP, phosphoprotein phosphatases; PR, primary root; PYL, PYR1-like; PYR1, pyrabactin resistance 1; RCAR, regulatory component of $A B A$ receptor; $R C N 1$, roots curl in n-naphthylphthalamic acid 1; ROS, reactive oxygen species; SLP, Shewanella-like protein phosphatase; SnRK2, SNF1-related protein kinase 2; TOPP1, type one protein phosphatase 1; YTH, yeast two-hybrid.

\section{Acknowledgements}

We are grateful to Professor J. Fronk for critical reading of the manuscript. We also thank Dr. Irute Meskiene for providing constructs for AP2C3 expression, Izabela Barymow for help with cultivating T87 cell lines and all members of our laboratory for stimulating discussions.

\section{Funding}

This work was supported by the Ministry of Science and Higher Education, Poland (grant 500/N-COST/2009/0 to GD) and National Science Centre (grant 2011/03/B/NZ3/00297 to GD). Funding in the laboratory of Pedro L. Rodriguez was provided by grant BIO2014-52537-R. Financial support from the EU (COST FA0605) is gratefully acknowledged.

\section{Availability of data and materials}

The data supporting the conclusions of this article are included within the article and its additional files. Materials described in the article will be freely available upon request to any scientist wishing to use them for noncommercial purposes.

\section{Authors' contributions}

E.K., M.B., P.L.R., M.D., and G.D. designed the experiments. E.K., M.B., A.K., A.C., M.L., J.D., A.L. generated lines and constructs and performed the experiments. E.K., M.B., A.K, M.D, P.L.R. and G.D. analyzed the data. E.K. and G.D. wrote the article. All authors revised the article. All authors read and approved the final manuscript.

\section{Competing interests}

The authors declare that they have no competing interests.

\section{Consent to publish}

Not applicable

\section{Ethics approval and consent to participate}

Not applicable

\section{Author details}

${ }^{1}$ Institute of Biochemistry and Biophysics, Polish Academy of Sciences, Pawińskiego 5a, 02-106 Warsaw, Poland. 'Present address: Nencki Institute of Experimental Biology, Polish Academy of Sciences, Pasteur 3, 02-093 Warsaw, Poland. ${ }^{3}$ Present address: Department of Chemistry, Warsaw University, Pasteur 1, 02-093 Warsaw, Poland. ${ }^{4}$ Department of Biotechnology, Institute of Molecular Biology and Biotechnology, Faculty of Biology, Adam Mickiewicz University in Poznań, Umultowska 89, 61-614 Poznań, Poland. ${ }^{5}$ Institute of Genetics and Biotechnology, University of Warsaw, Pawińskiego 5a, 02-106 Warsaw, Poland. ${ }^{6}$ Instituto de Biología Molecular y Celular de Plantas, Consejo Superior de Investigaciones Científicas-Universidad Politécnica de Valencia, ES-46022 Valencia, Spain.

Received: 11 December 2015 Accepted: 23 May 2016

Published online: 13 June 2016

References

1. Yamaguchi-Shinozaki K, Shinozaki K. Transcriptional regulatory networks in cellular responses and tolerance to dehydration and cold stresses. Annu Rev Plant Biol. 2006:57:781-803.

2. Roychoudhury A, Paul S, Basu S. Cross-talk between abscisic acid-dependent and abscisic acid-independent pathways during abiotic stress. Plant Cell Rep. 2013;32(7):985-1006.

3. Yoshida T, Mogami J, Yamaguchi-Shinozaki K. ABA-dependent and ABAindependent signaling in response to osmotic stress in plants. Curr Opin Plant Biol. 2014;21:133-9.

4. Fujii $\mathrm{H}$, Zhu JK. Arabidopsis mutant deficient in 3 abscisic acid-activated protein kinases reveals critical roles in growth, reproduction, and stress. Proc Natl Acad Sci U S A. 2009;106(20):8380-5.

5. Nakashima K, Fujita Y, Kanamori N, Katagiri T, Umezawa T, Kidokoro S, Maruyama K, Yoshida T, Ishiyama K, Kobayashi M, et al. Three Arabidopsis SnRK2 protein kinases, SRK2D/SnRK2.2, SRK2E/SnRK2.6/OST1 and SRK2I/ SnRK2.3, involved in ABA signaling are essential for the control of seed development and dormancy. Plant Cell Physiol. 2009;50(7):1345-63.

6. Fujita Y, Nakashima K, Yoshida T, Katagiri T, Kidokoro S, Kanamori N, Umezawa T, Fujita M, Maruyama K, Ishiyama K, et al. Three SnRK2 protein 
kinases are the main positive regulators of abscisic acid signaling in response to water stress in Arabidopsis. Plant Cell Physiol. 2009;50(12):212332.

7. Fujii $\mathrm{H}$, Verslues PE, Zhu JK. Arabidopsis decuple mutant reveals the importance of SnRK2 kinases in osmotic stress responses in vivo. Proc Nat Acad Sci U S A. 2011;108(4):1717-22.

8. Kulik A, Wawer I, Krzywinska E, Bucholc M, Dobrowolska G. SnRK2 protein kinases-key regulators of plant response to abiotic stresses. OMICS. 2011; 15(12):859-72.

9. Boudsocq $M$, Barbier-Brygoo $H$, Lauriere $C$. Identification of nine sucrose nonfermenting 1-related protein kinases 2 activated by hyperosmotic and saline stresses in Arabidopsis thaliana. J Biol Chem. 2004;279(40):41758-66.

10. Kobayashi Y, Yamamoto S, Minami H, Kagaya Y, Hattori T. Differential activation of the rice sucrose nonfermenting1-related protein kinase2 family by hyperosmotic stress and abscisic acid. Plant Cell. 2004;16(5):1163-77.

11. Melcher K, Zhou XE, XU HE. Thirsty plants and beyond: structural mechanisms of abscisic acid perception and signaling. Curr Opin Struct Biol. 2010;20(6):722-9.

12. Weiner JJ, Peterson FC, Volkman BF, Cutler SR. Structural and functional insights into core ABA signaling. Curr Opin Plant Biol. 2010;13(5):495-502.

13. Hubbard KE, Nishimura N, Hitomi K, Getzoff ED, Schroeder Jl. Early abscisic acid signal transduction mechanisms: newly discovered components and newly emerging questions. Genes Dev. 2010;24(16):1695-708.

14. Klingler JP, Batelli G, Zhu JK. ABA receptors: the START of a new paradigm in phytohormone signalling. J Exp Bot. 2010;61(12):3199-210.

15. Umezawa T, Nakashima K, Miyakawa T, Kuromori T, Tanokura M, Shinozaki K, Yamaguchi-Shinozaki K. Molecular basis of the core regulatory network in ABA responses: sensing, signaling and transport. Plant Cell Physiol. 2010; 51(11):1821-39.

16. Joshi-Saha A, Valon C, Leung J. Abscisic acid signal off the STARting block. Mol Plant. 2011;4(4):562-80.

17. Wang P, Xue L, Batelli G, Lee S, Hou YJ, Van Oosten MJ, Zhang H, Tao WA, Zhu JK. Quantitative phosphoproteomics identifies SnRK2 protein kinase substrates and reveals the effectors of abscisic acid action. Proc Natl Acad Sci U S A. 2013:110(27):11205-10.

18. Umezawa T, Sugiyama N, Takahashi F, Anderson JC, Ishihama Y, Peck SC, Shinozaki K. Genetics and phosphoproteomics reveal a protein phosphorylation network in the abscisic acid signaling pathway in Arabidopsis thaliana. Sci Signal. 2013;6(270):rs8.

19. Umezawa T, Yoshida R, Maruyama K, Yamaguchi-Shinozaki K, Shinozaki K. SRK2C, a SNF1-related protein kinase 2, improves drought tolerance by controlling stress-responsive gene expression in Arabidopsis thaliana. Proc Natl Acad Sci U S A. 2004;101(49):17306-11.

20. Mizoguchi M, Umezawa T, Nakashima K, Kidokoro S, Takasaki H, Fujita Y, Yamaguchi-Shinozaki K, Shinozaki K. Two closely related subclass II SnRK2 protein kinases cooperatively regulate drought-inducible gene expression. Plant Cell Physiol. 2010;51(5):842-7.

21. Burza AM, Pekala I, Sikora J, Siedlecki P, Malagocki P, Bucholc M, Koper L, Zielenkiewicz P, Dadlez M, Dobrowolska G. Nicotiana tabacum osmotic stress-activated kinase is regulated by phosphorylation on Ser-154 and Ser-158 in the kinase activation loop. J Biol Chem. 2006;281(45):34299-311.

22. McLoughlin F, Galvan-Ampudia CS, Julkowska MM, Caarls L, van der Does D, Lauriere C, Munnik T, Haring MA, Testerink C. The Snf1-related protein kinases SnRK2.4 and SnRK2.10 are involved in maintenance of root system architecture during salt stress. Plant J. 2012;72(3):436-49.

23. Belin C, de Franco PO, Bourbousse C, Chaignepain S, Schmitter JM, Vavasseur A, Giraudat J, Barbier-Brygoo H, Thomine S. Identification of features regulating OST1 kinase activity and OST1 function in guard cells. Plant Physiol. 2006;141(4):1316-27.

24. Boudsocg M, Droillard MJ, Barbier-Brygoo H, Lauriere C. Different phosphorylation mechanisms are involved in the activation of sucrose non-fermenting 1 related protein kinases 2 by osmotic stresses and abscisic acid. Plant Mol Biol. 2007;63(4): 491-503.

25. Vlad F, Droillard MJ, Valot B, Khafif M, Rodrigues A, Brault M, Zivy M, Rodriguez PL, Merlot S, Lauriere C. Phospho-site mapping, genetic and in planta activation studies reveal key aspects of the different phosphorylation mechanisms involved in activation of SnRK2s. Plant J. 2010;63(5):778-90.

26. Saruhashi M, Kumar Ghosh T, Arai K, Ishizaki Y, Hagiwara K, Komatsu K, Shiwa Y, Izumikawa K, Yoshikawa H, Umezawa T, et al. Plant Raf-like kinase integrates abscisic acid and hyperosmotic stress signaling upstream of SNF1-related protein kinase2. Proc Natl Acad Sci U S A. 2015:112(46): E6388-6396.
27. Cai Z, Liu J, Wang H, Yang C, Chen Y, Li Y, Pan S, Dong R, Tang G, BarajasLopez Jde D, et al. GSK3-like kinases positively modulate abscisic acid signaling through phosphorylating subgroup III SnRK2s in Arabidopsis. Proc Natl Acad Sci U S A. 2014;111(26):9651-6.

28. Umezawa T, Sugiyama N, Mizoguchi M, Hayashi S, Myouga F, YamaguchiShinozaki K, Ishihama Y, Hirayama T, Shinozaki K. Type 2C protein phosphatases directly regulate abscisic acid-activated protein kinases in Arabidopsis. Proc Natl Acad Sci U S A. 2009;106(41):17588-93.

29. Vlad F, Rubio S, Rodrigues A, Sirichandra C, Belin C, Robert N, Leung J, Rodriguez $\mathrm{PL}$, Lauriere $\mathrm{C}$, Merlot $\mathrm{S}$. Protein phosphatases $2 \mathrm{C}$ regulate the activation of the Snf1-related kinase OST1 by abscisic acid in Arabidopsis. Plant Cell. 2009;21(10):3170-84

30. Ma Y, Szostkiewicz I, Korte A, Moes D, Yang Y, Christmann A, Grill E. Regulators of PP2C phosphatase activity function as abscisic acid sensors. Science. 2009;324(5930):1064-8.

31. Melcher K, Ng LM, Zhou XE, Soon FF, Xu Y, Suino-Powell KM, Park SY, Weiner JJ, Fujii $H$, Chinnusamy $V$, et al. A gate-latch-lock mechanism for hormone signalling by abscisic acid receptors. Nature. 2009;462(7273): 602-8.

32. Miyazono K, Miyakawa T, Sawano Y, Kubota K, Kang HJ, Asano A, Miyauchi Y, Takahashi M, Zhi Y, Fujita Y, et al. Structural basis of abscisic acid signalling. Nature. 2009;462(7273):609-14.

33. Nishimura N, Hitomi K, Arvai AS, Rambo RP, Hitomi C, Cutler SR, Schroeder JI, Getzoff ED. Structural mechanism of abscisic acid binding and signaling by dimeric PYR1. Science. 2009;326(5958):1373-9.

34. Park SY, Fung P, Nishimura N, Jensen DR, Fujii H, Zhao Y, Lumba S, Santiago J, Rodrigues A, Chow TF, et al. Abscisic acid inhibits type 2C protein phosphatases via the PYR/PYL family of START proteins. Science. 2009:324(5930):1068-71.

35. Santiago J, Rodrigues A, Saez A, Rubio S, Antoni R, Dupeux F, Park SY, Marquez JA, Cutler SR, Rodriguez PL. Modulation of drought resistance by the abscisic acid receptor PYL5 through inhibition of clade A PP2Cs. Plant J. 2009:60(4):575-88.

36. Ng LM, Soon FF, Zhou XE, West GM, Kovach A, Suino-Powell KM, Chalmers MJ, Li J, Yong EL, Zhu JK, et al. Structural basis for basal activity and autoactivation of abscisic acid (ABA) signaling SnRK2 kinases. Proc Natl Acad Sci U S A. 2011:108(52):21259-64.

37. Soon FF, Ng LM, Zhou XE, West GM, Kovach A, Tan MH, Suino-Powell KM, He Y, Xu Y, Chalmers MJ, et al. Molecular mimicry regulates ABA signaling by SnRK2 kinases and PP2C phosphatases. Science. 2012;335(6064):85-8.

38. Zhou XE, Soon FF, Ng LM, Kovach A, Suino-Powell KM, Li J, Yong EL, Zhu JK, Xu $\mathrm{HE}$, Melcher K. Catalytic mechanism and kinase interactions of ABA-signaling PP2C phosphatases. Plant Signal Behav. 2012;7(5):581-8.

39. Kelner A, Pekala I, Kaczanowski S, Muszynska G, Hardie DG, Dobrowolska G. Biochemical characterization of the tobacco $42-\mathrm{kD}$ protein kinase activated by osmotic stress. Plant Physiol. 2004;136(2):3255-65.

40. Mikolajczyk M, Awotunde OS, Muszynska G, Klessig DF, Dobrowolska G. Osmotic stress induces rapid activation of a salicylic acid-induced protein kinase and a homolog of protein kinase ASK1 in tobacco cells. Plant Cell. 2000;12(1):165-78.

41. Nishimura N, Sarkeshik A, Nito K, Park SY, Wang A, Carvalho PC, Lee S, Caddell DF, Cutler SR, Chory J, et al. PYR/PYL/RCAR family members are major in-vivo ABI1 protein phosphatase $2 \mathrm{C}$-interacting proteins in Arabidopsis. Plant J. 2010;61(2):290-9.

42. Ludwikow A, Ciesla A, Kasprowicz-Maluski A, Mitula F, Tajdel M, Galganski L, Ziolkowski PA, Kubiak P, Malecka A, Piechalak A, et al. Arabidopsis protein phosphatase 2C ABI1 interacts with type I ACC synthases and is involved in the regulation of ozone-induced ethylene biosynthesis. Mol Plant. 2014;7(6): 960-76.

43. Bialojan C, Takai A. Inhibitory effect of a marine-sponge toxin, okadaic acid, on protein phosphatases. Specificity and kinetics. Biochem J. 1988;256(1): 283-90.

44. Yoshida R, Hobo T, Ichimura K, Mizoguchi T, Takahashi F, Aronso J, Ecker JR, Shinozaki K. ABA-activated SnRK2 protein kinase is required for dehydration stress signaling in Arabidopsis. Plant Cell Physiol. 2002:43(12):1473-83.

45. Xie T, Ren R, Zhang YY, Pang Y, Yan C, Gong X, He Y, Li W, Miao D, Hao Q, et al. Molecular mechanism for inhibition of a critical component in the Arabidopsis thaliana abscisic acid signal transduction pathways, SnRK2.6, by protein phosphatase ABI1. J Biol Chem. 2012;287(1):794-802.

46. Duan L, Dietrich D, Ng CH, Chan PM, Bhalerao R, Bennett MJ, Dinneny JR. Endodermal ABA signaling promotes lateral root quiescence during salt stress in Arabidopsis seedlings. Plant Cell. 2013;25(1):324-41. 
47. Lynch T, Erickson BJ, Finkelstein RR. Direct interactions of ABA-insensitive(ABI)clade protein phosphatase(PP)2Cs with calcium-dependent protein kinases and $A B A$ response element-binding bZIPs may contribute to turning off $A B A$ response. Plant Mol Biol. 2012;80(6):647-58.

48. Zhang $H$, Liu WZ, Zhang Y, Deng M, Niu F, Yang B, Wang X, Wang B, Liang W, Deyholos MK, et al. Identification, expression and interaction analyses of calcium-dependent protein kinase (CPK) genes in canola (Brassica napus L.). BMC Genomics. 2014;15:211.

49. Hao Q, Yin P, Li W, Wang L, Yan C, Lin Z, Wu JZ, Wang J, Yan SF, Yan N. The molecular basis of ABA-independent inhibition of PP2Cs by a subclass of PYL proteins. Mol Cell. 2011;42(5):662-72.

50. Li J, Shi C, Sun D, He Y, Lai C, Lv P, Xiong Y, Zhang L, Wu F, Tian C. The HAB1 PP2C is inhibited by ABA-dependent PYL10 interaction. Sci Rep. 2015;5:10890

51. Antoni R, Gonzalez-Guzman M, Rodriguez L, Rodrigues A, Pizzio GA, Rodriguez PL. Selective inhibition of clade A phosphatases type $2 \mathrm{C}$ by PYR/PYL/RCAR abscisic acid receptors. Plant Physiol. 2012;158(2):970-80.

52. Pizzio GA, Rodriguez L, Antoni R, Gonzalez-Guzman M, Yunta C, Merilo E, Kollist H, Albert A, Rodriguez PL. The PYL4 A194T mutant uncovers a key role of PYR1-LIKE4/PROTEIN PHOSPHATASE 2CA interaction for abscisic acid signaling and plant drought resistance. Plant Physiol. 2013;163(1):441-55.

53. Lan WZ, Lee SC, Che YF, Jiang YQ, Luan S. Mechanistic analysis of AKT1 regulation by the CBL-CIPK-PP2CA interactions. Mol Plant. 2011;4(3):527-36.

54. Zhang W, Qin C, Zhao J, Wang X. Phospholipase D alpha 1-derived phosphatidic acid interacts with $\mathrm{AB} 11$ phosphatase $2 \mathrm{C}$ and regulates abscisic acid signaling. Proc Natl Acad Sci U S A. 2004;101(25):9508-13.

55. Meinhard M, Grill E. Hydrogen peroxide is a regulator of $A B \mid 1$, a protein phosphatase 2C from Arabidopsis. FEBS Lett. 2001;508(3):443-6.

56. Sridharamurthy M, Kovach A, Zhao Y, Zhu JK, XU HE, Swaminathan K, Melcher K. H2O2 inhibits ABA-signaling protein phosphatase HAB1. PLoS One. 2014;9(12):e113643.

57. Zhu M, Zhu N, Song WY, Harmon AC, Assmann SM, Chen S. Thiol-based redox proteins in abscisic acid and methyl jasmonate signaling in Brassica napus guard cells. Plant J. 2014;78(3):491-515.

58. Wang $P, D u Y$, Hou YJ, Zhao Y, Hsu CC, Yuan F, Zhu X, Tao WA, Song CP, Zhu JK. Nitric oxide negatively regulates abscisic acid signaling in guard cells by S-nitrosylation of OST1. Proc Natl Acad Sci U S A. 2015;112(2):613-8.

59. Davies SP, Helps NR, Cohen PT, Hardie DG. 5'-AMP inhibits dephosphorylation, as well as promoting phosphorylation, of the AMP-activated protein kinase. Studies using bacterially expressed human protein phosphatase-2C alpha and native bovine protein phosphatase-2 AC. FEBS Lett. 1995;377(3):421-5.

60. Sanders MJ, Grondin PO, Hegarty BD, Snowden MA, Carling D. Investigating the mechanism for AMP activation of the AMP-activated protein kinase cascade. Biochem J. 2007;403(1):139-48.

61. Wu Y, Song P, Xu J, Zhang M, Zou MH. Activation of protein phosphatase 2A by palmitate inhibits AMP-activated protein kinase. J Biol Chem. 2007; 282(13):9777-88.

62. Garcia-Haro L, Garcia-Gimeno MA, Neumann D, Beullens M, Bollen M, Sanz P. The PP1-R6 protein phosphatase holoenzyme is involved in the glucose-induced dephosphorylation and inactivation of AMP-activated protein kinase, a key regulator of insulin secretion, in MIN6 beta cells. FASEB J. 2010;24(12):5080-91.

63. Wang T, Yu Q, Chen J, Deng B, Qian L, Le Y. PP2A mediated AMPK inhibition promotes HSP70 expression in heat shock response. PLOS One. 2010;5(10):e13096.

64. Schmidt C, Schelle I, Liao YJ, Schroeder JI. Strong regulation of slow anion channels and abscisic acid signaling in guard cells by phosphorylation and dephosphorylation events. Proc Natl Acad Sci U S A. 1995;92(21):9535-9.

65. Kwak JM, Moon JH, Murata Y, Kuchitsu K, Leonhardt N, DeLong A, Schroeder Jl. Disruption of a guard cell-expressed protein phosphatase $2 \mathrm{~A}$ regulatory subunit, RCN1, confers abscisic acid insensitivity in Arabidopsis. Plant Cell. 2002;14(11): 2849-61.

66. Pernas M, Garcia-Casado G, Rojo E, Solano R, Sanchez-Serrano JJ. A protein phosphatase 2A catalytic subunit is a negative regulator of abscisic acid signalling. Plant J. 2007:51(5):763-78.

67. Xu C, Jing R, Mao X, Jia X, Chang X. A wheat (Triticum aestivum) protein phosphatase $2 \mathrm{~A}$ catalytic subunit gene provides enhanced drought tolerance in tobacco. Ann Bot. 2007;99(3):439-50.

68. Blakeslee JJ, Zhou HW, Heath JT, Skottke KR, Barrios JA, Liu SY, DeLong A. Specificity of RCN1-mediated protein phosphatase 2A regulation in meristem organization and stress response in roots. Plant Physiol. 2008; 146(2):539-53.
69. Pais SM, Gonzalez MA, Tellez-Inon MT, Capiati DA. Characterization of potato (Solanum tuberosum) and tomato (Solanum lycopersicum) protein phosphatases type 2A catalytic subunits and their involvement in stress responses. Planta. 2009;230(1):13-25.

70. Ogawa D, Abe K, Miyao A, Kojima M, Sakakibara H, Mizutani M, Morita H, Toda Y, Hobo T, Sato Y, et al. RSS1 regulates the cell cycle and maintains meristematic activity under stress conditions in rice. Nat Commun. 2011;2:278.

71. Dai M, Xue Q, McCray T, Margavage K, Chen F, Lee JH, Nezames CD, Guo L, Terzaghi W, Wan J, et al. The PP6 phosphatase regulates ABI5 phosphorylation and abscisic acid signaling in Arabidopsis. Plant Cell. 2013; 25(2):517-34.

72. Waadt R, Manalansan B, Rauniyar N, Munemasa S, Booker MA, Brandt B, Waadt C, Nusinow DA, Kay SA, Kunz HH, et al. Identification of Open Stomata1-Interacting Proteins Reveals Interactions with Sucrose Nonfermenting1-Related Protein Kinases2 and with Type 2A Protein Phosphatases That Function in Abscisic Acid Responses. Plant Physiol. 2015; 169(1):760-79

73. Hou YJ, Zhu Y, Wang P, Zhao Y, Xie S, Batelli G, Wang B, Duan CG, Wang X, Xing $L$, et al. Type One Protein Phosphatase 1 and Its Regulatory Protein Inhibitor 2 Negatively Regulate ABA Signaling. PLoS Genet. 2016;12(3): e1005835.

74. Uhrig RG, Labandera AM, Moorhead GB. Arabidopsis PPP family of serine/ threonine protein phosphatases: many targets but few engines. Trends Plant Sci. 2013;18(9):505-13.

75. Dai M, Zhang C, Kania U, Chen F, Xue Q, McCray T, Li G, Qin G, Wakeley M, Terzaghi W, et al. A PP6-type phosphatase holoenzyme directly regulates PIN phosphorylation and auxin efflux in Arabidopsis. Plant Cell. 2012;24(6): 2497-514.

76. Ludwikow A, Kierzek D, Gallois P, Zeef L, Sadowski J. Gene expression profiling of ozone-treated Arabidopsis abi1td insertional mutant: protein phosphatase $2 \mathrm{C}$ ABl1 modulates biosynthesis ratio of $\mathrm{ABA}$ and ethylene. Planta. 2009;230(5):1003-17.

77. Kulik A, Anielska-Mazur A, Bucholc M, Koen E, Szymanska K, Zmienko A, Krzywinska E, Wawer I, McLoughlin F, Ruszkowski D, et al. SNF1-related protein kinases type 2 are involved in plant responses to cadmium stress. Plant Physiol. 2012;160(2):868-83.

78. Yamada H, Koizumi N, Nakamichi N, Kiba T, Yamashino T, Mizuno T. Rapid response of Arabidopsis T87 cultured cells to cytokinin through His-to-Asp phosphorelay signal transduction. Biosci Biotechnol Biochem. 2004;68(9): 1966-76.

79. Bucholc M, Ciesielski A, Goch G, Anielska-Mazur A, Kulik A, Krzywinska E, Dobrowolska G. SNF1-related protein kinases 2 are negatively regulated by a plant-specific calcium sensor. J Biol Chem. 2011;286(5):3429-41.

80. Chen DC, Yang BC, Kuo $\Pi$. One-step transformation of yeast in stationary phase. Curr Genet. 1992;21(1):83-4.

81. Umbrasaite J, Schweighofer A, Kazanaviciute V, Magyar Z, Ayatollahi Z, Unterwurzacher V, Choopayak C, Boniecka J, Murray JA, Bogre L, et al. MAPK phosphatase AP2C3 induces ectopic proliferation of epidermal cells leading to stomata development in Arabidopsis. PLoS One. 2010;5(12):e15357.

82. Frangioni JV, Neel BG. Solubilization and purification of enzymatically active glutathione S-transferase (pGEX) fusion proteins. Anal Biochem. 1993;210(1): 179-87.

83. Zhang S, Klessig DF. Salicylic acid activates a 48-kD MAP kinase in tobacco. Plant Cell. 1997;9(5):809-24.

84. Tzfira T, Tian GW, Lacroix B, Vyas S, Li J, Leitner-Dagan Y, Krichevsky A, Taylor T, Vainstein A, Citovsky V. pSAT vectors: a modular series of plasmids for autofluorescent protein tagging and expression of multiple genes in plants. Plant Mol Biol. 2005;57(4):503-16.

85. Martin K, Kopperud K, Chakrabarty R, Banerjee R, Brooks R, Goodin MM. Transient expression in Nicotiana benthamiana fluorescent marker lines provides enhanced definition of protein localization, movement and interactions in planta. Plant J. 2009;59(1):150-62.

86. Wu FH, Shen SC, Lee LY, Lee SH, Chan MT, Lin CS. Tape-Arabidopsis Sandwich - a simpler Arabidopsis protoplast isolation method. Plant Methods. 2009;5:16. 